American Journal of Pharmaceutical Education 2018; 82 (5) Article 6279.

\title{
RESEARCH
}

\section{A Comparison of Approaches to Student Pharmacist Business Planning in Pharmacy Practice Management}

\author{
Justin Gatwood, PhD, MPH, ${ }^{\mathrm{a}}$ Kenneth Hohmeier, PharmD, ${ }^{\mathrm{a}}$ Glen Farr, PharmD, ${ }^{\mathrm{a}}$ \\ Stephen Eckel, PharmD, MHA ${ }^{\mathrm{b}}$ \\ ${ }^{\text {a }}$ University of Tennessee College of Pharmacy, Nashville, Tennessee \\ ${ }^{\mathrm{b}}$ University of North Carolina Eshelman School of Pharmacy, Chapel Hill, North Carolina \\ Submitted January 14, 2017; accepted February 21, 2017; published June 2018.
}

Objective. To compare second-year student pharmacists' perspectives on two approaches for completing a pharmacy practice management business planning project.

Methods. A mixed-methods approach was used to compare two options (traditional and experimental) for completing business plan projects that were offered to teams of second-year student pharmacists as part of a required pharmacy management course. Teams who chose the traditional project were required to develop a unique, pharmacy-related business plan while those who chose the experimental concept were paired with a pharmacy-focused firm within Tennessee and tasked with designing a potential service for the firm's consideration. At semester's end, all students were asked to complete a brief survey to provide insight on their experiences with either of the group projects. Students and firm stakeholders were also asked to participate in a group and individual interview, respectively.

Results. Student group comparisons indicated that the experimental project provided a more realworld, business planning experience. Additionally, groups that did the experimental project were more likely to report seeing how business and pharmacy practice were connected, indicate a better understanding of the principles of pharmacy management, and be perceived as more marketable for a future pharmacy career. Firm representatives indicated that insight provided by the students was valuable and that they had plans to implement what was proposed.

Conclusion. Connecting student pharmacists with a pharmacy-focused firm provided a real-world management experience that better complemented the course's principles, and created a mutually beneficial innovation-focused partnership.

Keywords: pharmacy management, innovation, teamwork, entrepreneurship

\section{INTRODUCTION}

Experiential education has been a staple of pharmacy education as a vital element of the learning process for student pharmacists. Provided by Introductory Pharmacy Practice Experiences (IPPE) and Advanced Pharmacy Practice Experiences (APPE), direct exposure assists degree candidates in transitioning toward pharmacy practice, providing a bridge between didactic instruction and real-world applications. As may be expected and required, much, if not all, of the focus for these experiences is the development of clinical skills; however, abilities beyond those mastered in therapeutics and similar coursework are needed to become a successful practitioner. In recognition of this and as dictated by accrediting bodies,

Corresponding Author: Justin Gatwood, University of Tennessee College of Pharmacy, 193 Polk Ave., Suite 2D, Nashville, TN 37210. Tel: 615-532-3403. Fax: 615-532-3399. E-mail: jgatwood@uthsc.edu colleges of pharmacy require graduates to complete coursework focused on practice management, training which crosses multiple domains outlined by the most recent Center for the Advancement of Pharmacy Education (CAPE) outcomes and reinforced by the Accreditation Council for Pharmacy Education (ACPE) ${ }^{1,2}$ Specifically, curricular content is expected to include material that encourages innovation and entrepreneurship (CAPE 4.3) as well as problem-solving (CAPE 3.1) where learning objectives stress initiative, creative decision making, and a step-wise approach to identifying, considering, and implementing solutions, among others. ${ }^{1}$ To address these expectations, content of practice management courses commonly include operations management, human resources, finance, quality improvement, and other universal topics critical to pharmacy practice. Additionally, themes central to effective management are often included, such as leadership, team building, conflict resolution, and negotiation techniques. 


\section{American Journal of Pharmaceutical Education 2018; 82 (5) Article 6279.}

As has been pointed out, what may challenge effective student learning - unlike more clinically focused courses - is the lack of context for immediate, practical application of the information offered. ${ }^{3}$ While exposure to material in the pharmacy management classroom may form the basis for foundational knowledge in business, economics, or management, significant learning cannot take place without integration of other approaches that may lead to improved learning. ${ }^{4}$ Consequently, skills deemed critically important by accrediting bodies may not be as fully absorbed as those which were applied in real-world scenarios during APPE rotations (ie, leveraging higher-level concepts outlined by Bloom's taxonomy). ${ }^{5}$ Although some APPE placements may provide more in-depth exposure to the business and managerial aspects of pharmacy practice, this is not a universal requirement for all students nor may it be operationally feasible for all schools.

Entrepreneurial educators have recognized a similar issue in their field, suggesting the increased need for inserting students into actual environments rather than relying on existing information to provide instruction on entrepreneurship within the confines of the classroom. ${ }^{6,7}$ While innovation may play a more central role in entrepreneurship education, it would be a missed opportunity to not leverage what has been observed by colleges of business in adequately responding to calls for improved focus on developing entrepreneurial skills. ${ }^{6,7}$ To do so, pharmacy instructors may need to leverage innovative approaches to assist students in fully absorbing managerial material crucial to their success as future practitioners. This includes considering the content and techniques used by non-medical disciplines as they may provide valuable guidance. For example, business schools across the United States have regularly used consulting projects as an active learning mechanism to connect in-class material with real-world experience, the process for which having been fully outlined for schools to model. ${ }^{8}$ This field-based exercise places students with firms in the area and requires them to perform team-based problem solving in an active business environment. Consequently, students gain valuable experience in needs assessment, problem solving, small group dynamics, project management, and concept presentation. ${ }^{9}$ Moreover, multiple benefits are realized by the partnering firm as well, having received potentially valuable recommendations through third-party analysis. ${ }^{10,11} \mathrm{Argu}-$ ably, those same experiences could serve to benefit student pharmacists and pharmacy-focused firms should a similar model be leveraged by pharmacy educators. The objective of this study was to determine whether direct exposure to real-world problems may better wed classroom instruction with practical applications when compared to a traditional business plan exercise. This study describes the quantitative comparisons between such an applied business planning project and a traditional business plan and provides perspective from both students and stakeholders who piloted the applied project.

\section{METHODS}

In the spring 2016 semester, the second-year pharmacy student class $(\mathrm{N}=163)$ was given two options to complete a semester-long, team-based business planning project. The first option (control), a more traditional business plan project, was one that has been required in recent years: students were assigned to teams early in the semester at each campus who would then work together to formulate, draft, and present a formal pharmacy-related business plan to their peers - a popular mechanism among pharmacy schools that has demonstrated significant value. ${ }^{12,13}$ Specifically, the plan would involve researching a concept and its potential market, developing mission and vision statements, describing the potential product or service of their choosing, formulating a marketing plan, and estimating the cash flow for the business or service. The culmination of the project was an eight- to ten-page paper formatted in a manner similar to that outlined by Schumock and Stubbings, and evaluated based on criteria suggested by the National Community Pharmacists Association (NCPA). ${ }^{14,15}$ Additionally, the project would require the construction of a formal strengths, weaknesses, opportunities, threats (SWOT) analysis, cash flow estimates, and sample marketing materials. The course is not structured to provide step-by-step instruction on how to formulate a business plan but elements important to its creation were interspersed throughout the term to guide development. Also, limited classroom time is given to groups to work on this project but one lecture early in the semester was devoted to instructing students on how to structure the business plan. Both the presentation and its accompanying paper are then evaluated by course instructors and a group grade given after considering peer evaluations on individual effort.

The second option offered in 2016 was experimental and involved the completion of a more applied group project similar to those employed in recent years by schools of pharmacy at the University of Toledo, Texas Southern University, and the University of North Carolina. ${ }^{16,17}$ In these earlier instances, teams of students were paired with pharmacy managers and other key stakeholders in a variety of practice environments. Each team was then tasked with designing a proposal for a defined pharmacy service, such as pharmaceutical care or medication 


\section{American Journal of Pharmaceutical Education 2018; 82 (5) Article 6279.}

therapy management (MTM) services, as outlined by the pharmacy manager or stakeholder. ${ }^{16,17}$ Using these examples as models, a comparable concept was piloted by partnering with several firms across Tennessee. Similar to these earlier concepts, the purpose was to expose students to the operations of an actual pharmacy-focused firm so they could provide third-party insight and an innovative solution. However, a key component of this model was that student groups were tasked with identifying an area of opportunity for their assigned firm and then providing a new idea rather than taking a company-suggested concept and building a related proposal. In so doing, the intention was to better incorporate all elements of Fink's taxonomy into a valuable experience that may lead to improved context for and learning of pharmacy practice management principles while being concurrently entrepreneurial. ${ }^{4}$

Initially, three firms were approached (an independent compounding pharmacy, a children's hospital, and a charitable pharmacy) to provide equity across campuses, but, in anticipation of excess demand, two additional companies were asked to participate (a regional community pharmacy chain and an MTM service provider). At the beginning of the semester, students selfselected into groups of six or seven members, regardless of project type, and all teams were given the opportunity to volunteer for an experimental project concept. Interested teams were then matched to the firm in their region (with one exception), and all five partner companies were eventually involved. Once matched, an initial meeting was conducted between the student team and the firm's key contact, either on site or using telepresence. At this meeting, the firm was tasked with providing sufficient details on their mission and vision, operations, and finances so that the student group could then conceptualize a novel concept for the firm's eventual consideration. Following, each team was required to perform a needs assessment to guide their concept development throughout the term. While the firm's key contact was available throughout the semester to answer questions, the expectation was that the student groups would work independent of the company's assistance. At the end of the semester, a final paper was required of each team, the content and formatting of which was expected to be similar, but not identical to, that required of their peers' who completed the traditional project (control); however, the length of the paper was expected to be the same as the requirements for the traditional project. A key difference between the project types was that the experimental project teams were required to present to their partnering firm (involving stakeholders of the firm's choosing) rather than to their classmates. Most of these presentations took place at University of Tennessee College of Pharmacy
(UTCOP) facilities, but one team chose to go on site and present directly to their key contacts. Regardless of location, all experimental project presentations were recorded and edited for viewing during class by all students at the end of the semester. Final papers and presentations for the experimental groups were evaluated using a rubric similar to that used for the traditional projects.

To assess impact and collect feedback on the experimental project concept, a mixed methods approach was used. At the conclusion of the semester, all students enrolled in the course were asked to complete an electronic survey that focused on experiences with the business plan project (external to the typical course evaluation). The instrument included 22 items, the majority of which were adapted from a survey used to assess students' perception of a required senior research project. ${ }^{18}$ Nearly all items were asked using a 5-point Likert scale, ranging from strongly disagree to strongly agree, and responses were assigned a coded identifier by Qualtrics Research Suite (Qualtrics LLC, Provo, UT) to protect student anonymity. Differences in student responses were assessed using the Mantel-Haenszel test for linear trend between the project types.

Additionally, students who opted to complete an experimental project were asked to participate in a focus group conducted by a faculty member without administrative authority over the course After the completion of the course and presentations to the respective firms, participants were asked to respond to questions and then discuss their experiences with the experimental business plan project, specifically focusing on why they chose this type of project, likes, dislikes, and the perceived value of the experience. Concurrently, the course director personally interviewed partnering firm stakeholders willing to provide feedback on the experience of working with a student group. They were asked to reflect on their interactions with the student group, what they found successful about the program, their challenges, the likelihood of implementing what was proposed, and their resulting impression of the college and its students. Interview questions for both the individual and group sessions were developed internally based upon the course director's discussions with other pharmacy faculty members, and the study team reviewed two iterations of the protocol before revisions were finalized. All sessions were conducted and recorded using Zoom audio-visual technology (Zoom Video Communications, San Jose, CA). Following, the interviews were transcribed and entered into NVivo version 10 (QSR International, Melbourne, Australia) for interpretation. Thematic analysis was performed to analyze the data and reduce the transcripts into themes. Two study team members independently coded the data from 


\section{American Journal of Pharmaceutical Education 2018; 82 (5) Article 6279.}

each session into themed categories using open coding and axial coding. The researchers then met to compare their independently-generated codes, discuss potential emerging themes, and reach agreement on major themes. Coding and analysis continued to refine and organize the categories of themes in the data until agreement was reached. All methods used were approved by the University of Tennessee Health Science Center Institutional Review Board.

\section{RESULTS}

Out of a class of 163 students, 24 groups were created with five groups $(\mathrm{N}=34$ students) opting for the experimental project. A total of 121 students $(74.2 \%)$ responded to the survey at the end of the semester. Although the experimental project concept was volunteer-based and the students self-selected groups, no significant differences existed between students of each project type in terms of items evaluating entrepreneurial interests $(28.0 \%$ experimental versus $29.2 \%$ traditional, $p=.619$ ), suggesting that those interested in entrepreneurship were likely well-distributed among the project types. A majority (74.3\%) of all students agreed or strongly agreed that the project was relevant to what was presented throughout the course while approximately two-thirds of the students $(62.0 \%)$ enjoyed (agreed or strongly agreed) working on the project (Table 1). Additionally, the vast majority of all students were pleased (agreed or strongly agreed) with the idea their group proposed ( $85.9 \%)$, and nearly all $(94.2 \%)$ were proud of their team's final product. For these items, no differences were determined between respondents by project type.

However, numerous notable differences in responses were observed between students who completed the experimental versus the traditional (control) project. Students who completed the experimental project overwhelmingly reported that this exercise provided a real-world learning experience: $92.0 \%$ agreed or strongly agreed versus $43.7 \%$ among those completing the traditional project $(p<.0001)$. Additionally, that same percentage of experimental groups reported agreement or strong agreement to seeing how business and pharmacy practice are connected (versus $51.1 \%$ among students in traditional project groups; $p<.0001$ ), and $68.0 \%$ of students in experimental project groups agreed or strongly agreed that their project experience helped them better understand the principles of pharmacy management, compared with only $40.7 \%$ among students in the traditional project groups $(p<.01)$. Importantly, over half of students $(52.0 \%)$ in experimental project groups agreed or strongly agreed that they were more marketable for a future pharmacy career following completion of the business plan project versus less than one-third $(29.2 \%)$ of their peers completing the traditional option $(p<.01)$. Students in experimental project groups also reported significantly higher agreement with the project having provided a valuable learning experience $(76.0 \%$ vs $50.0 \%, p<.01)$, and an ability to visualize how the skills developed during the project would apply to a future pharmacy career $(60.0 \%$ vs $40.7 \%$, $p<.05)$. Additionally, greater interest in future coursework on pharmacy entrepreneurship (36.0\% vs $25.0 \%, p<.05)$ was observed among students in experimental project groups (not shown).

Of the five student-firm experimental group pairs, four pairs were available and participated in the focus groups (students) or interviews (stakeholders). Fourteen students and four stakeholders (each from individual firms) participated; focus groups lasted from 22 to 32 minutes while the interviews ran 12 to 19 minutes. Several themes emerged from the group and individual interviews (Table 2). Notably, the students perceived that the experimental project provided them a real-world experience. Initially, this was what had attracted them to the concept; however, once the project was underway, this real-world theme was associated with both positive and negative perceptions and were closely related to themes 4 (navigating ambiguity), 6 (struggle and growth), and 7 (positive overall experience). Furthermore, the students realized that this project had the capability to make a real impact within the organization; therefore, their hard work would be realized as a positive impact on the partnering organization (Theme 1). However, this also meant that the students were accountable to more than their professor, and that the result of poor performance was more than a poor grade. Moreover, students perceived long-term value of the pilot project beyond of the course or semester. Namely, students felt that it contributed to components of career development: networking and curriculum vitae building (Theme 2).

Students also noted that their idea of a team expanded beyond solely the students involved in the project. Since the project involved coordination with one or several members of a pharmacy organization, their approach to completing the project changed. Importantly, they noted that working with the busy schedules of the partner organizations sometimes made teamwork difficult, especially when there were delays in communication on the part of the organization. The result was students realizing that the difficulty in accomplishing a project is sometimes related more to communication issues between student and pharmacist team members than with the actual creation of a business plan (Theme 3 ).

A major student concern was the navigation of ambiguous or "gray" areas during the project, which initially drove some students to choose the applied project over the traditional exercise (Theme 4). Students noted their discomfort for the sometimes inherent ambiguities in the development of a new service, but in many circumstances, 


\section{American Journal of Pharmaceutical Education 2018; 82 (5) Article 6279.}

Table 1. Comparisons of Student Project Perspectives

\begin{tabular}{|c|c|c|c|}
\hline \multirow[b]{3}{*}{ Survey Item } & \multicolumn{2}{|c|}{ Agreement $^{\mathrm{a}}$} & \multirow[b]{3}{*}{$p$ value } \\
\hline & $\begin{array}{l}\text { Experimental } \\
(\mathrm{N}=\mathbf{2 5})\end{array}$ & $\begin{array}{l}\text { Traditional } \\
\quad(\mathrm{N}=96)\end{array}$ & \\
\hline & n (\%) & n (\%) & \\
\hline The business plan project provided a valuable learning experience & $19(78.0)$ & $48(50.0)$ & .006 \\
\hline The business plan project was relevant to what was presented in class & $21(84.0)$ & $69(71.9)$ & .163 \\
\hline $\begin{array}{l}\text { The business plan project allowed me to see how business and } \\
\text { pharmacy practice are connected }\end{array}$ & $23(92.0)$ & $49(51.1)$ & $<.0001$ \\
\hline $\begin{array}{l}\text { The business plan project helped me better understand the principles } \\
\text { of pharmacy management }\end{array}$ & $17(68.0)$ & $39(40.7)$ & .002 \\
\hline $\begin{array}{l}\text { The business plan project provided me with a real-world learning } \\
\text { experience }\end{array}$ & $23(92.0)$ & $42(43.7)$ & $<.0001$ \\
\hline I enjoyed working on the business plan project with my team & $18(72.0)$ & $57(59.4)$ & .141 \\
\hline $\begin{array}{l}\text { I was pleased with my team's selection of a topic for the business } \\
\text { plan proposal }\end{array}$ & $20(80.0)$ & $84(87.5)$ & .711 \\
\hline $\begin{array}{l}\text { The amount of work required of the business plan project was } \\
\text { appropriate for the credit received }\end{array}$ & $15(60.0)$ & $34(35.4)$ & .019 \\
\hline $\begin{array}{l}\text { I struggled with effectively contributing to my team's business } \\
\text { plan project }\end{array}$ & $3(12.0)$ & $7(7.3)$ & .783 \\
\hline I am proud of my team's final business proposal & $24(96.0)$ & $90(93.8)$ & .653 \\
\hline $\begin{array}{l}\text { The instructors should continue to require the business plan } \\
\text { project as a major part of the management course }\end{array}$ & $11(44.0)$ & $31(32.3)$ & .068 \\
\hline $\begin{array}{l}\text { I believe I am more marketable for a future pharmacy career after } \\
\text { completing the business plan project }\end{array}$ & $13(52.0)$ & $28(29.2)$ & .001 \\
\hline $\begin{array}{l}\text { After completing the business plan project I am more likely to } \\
\text { propose a new pharmacy-related product or service in my future } \\
\text { pharmacy career }\end{array}$ & $8(32.0)$ & $24(25.0)$ & .053 \\
\hline $\begin{array}{l}\text { Based on my current career plans, I can see where I would apply } \\
\text { the skills I acquired during the business plan project to my future, } \\
\text { desired position }\end{array}$ & $15(60.0)$ & $39(40.7)$ & .015 \\
\hline
\end{tabular}

${ }^{a}$ Values represent the count (\%) of those responding "Agree" or "Strongly Agree" to each item

their perceptions and initial assumptions were challenged. Consequently, they found that organizations were much more complex than they appeared to be on the surface.

Students also indicated that they were often expected to draw upon their prior pharmacy education experiences to think critically about solutions to the problems presented by the firm (Theme 5). In most situations, the firm presented a problem which needed both the students' in- sights and assistance with - it was not pure delegation of a solution that needed to be implemented. The firm typically began with a presentation of a basic concept, and then, once presented with sufficient information on the firm, it was up to the group to determine how to address the needs of their partner organization - in line with the objective of this type of exercise. This led to some frustration among the groups but also forced each team to 


\section{American Journal of Pharmaceutical Education 2018; 82 (5) Article 6279.}

Table 2. Student Feedback Themes and Select Responses Related to the Experimental Project

\begin{tabular}{ll}
\hline Theme & Commentary \\
\hline 1. Real-world experience & ". it was kind of a cool opportunity to work with like an actual business." \\
& "I think we chose to do the pilot [project] versus the traditional [project] because we wanted our \\
& work and effort task to feel like it was going towards something and not necessarily just some make \\
believe random thing that we may never do anything about it ever again."
\end{tabular}

2. Career development

"We want to do something tangible that we have and now we have that, not only that, we have connections as well with very many people, [pharmacist preceptor] has been awesome to us and it's great to have their connections for our careers in the future."

3. Teamwork

"We had to be very creative and how we approached [the project] together as a team... We had to be very creative in how we designed our project and had to work together as a team to kind of figure [our plan] out and make sure we were on the same page. So it was a good group team strengthening exercise."

“... trying to coordinate with six group members, coordinating with work schedule, class schedule, etc., is kind of a challenge with the delay in response [from the pharmacists at the partner organization]."

4. Navigating ambiguity "My least favorite thing was kind of there were no set expectations or guidelines of what we were tasked with... So it was just kind of stressful because we saw all the other groups like checking their list off of what they had to do, who had to do what, and we really didn't start to do that until a few weeks before the end of the semester when the project was due."

5. Problem solving/critical "Right now [the partner pharmacy organization] is in an identity crisis. They really are struggling in thinking the community world as far as the volume of the prescriptions they fill, [and] they are looking for ways to distinguish themselves in that world and [eventually we] had an idea that the community pharmacogenomic test could do that."

6. Struggle and growth

"I think that I enjoyed figuring out how to maneuver this project. Although it was frustrating, I think at the end being able to have successfully complete it was extremely satisfying as far as that we are capable of thinking in this sort of business mind set."

"You just kind of have to figure it out together. So I think that was a good experience for us, that some of the other groups didn't get because they had set expectations and guidelines and checklists. So that was a good experience, that was probably what I valued the most of our project."

7. Positive overall experience "I think it opened our eyes to like 'Alright, this is something possibly that is out there for us.' So I think maybe the experience overall is what I enjoyed most."

work together to conceptualize and then defend a viable solution within a defined environment rather than operating within set expectations and rubrics that their peers completing the traditional project had at their disposal. As mentioned previously, ambiguity provided some anxiety among students, but, after completing the project and reflecting on this particular challenge, it was felt that the exposure to situations like this generated personal growth not seen by students participating in the traditional project (Theme 6).

Students had many suggestions to improve the project, but these suggestions for improvement were typical of the struggles one has when working on projects in a real-world setting. For instance, throughout the semester they were exposed to the typical communication issues that are standard in project work, such as conflicting schedules and the need to coordinate both student and stakeholder time. This forced them to ask more careful questions and be more cognizant of their own accountability when communicating their needs and questions. In many instances, the students had an expectation that communication with the organization would be semiinstantaneous. However, in many situations they found it would take days and up to a week or more before they 


\section{American Journal of Pharmaceutical Education 2018; 82 (5) Article 6279.}

had a response to electronic correspondence. The students had to adapt to the response turnaround times, and plan accordingly to meet deadlines. However, despite these challenges and struggles that were seemingly unrelated to pharmacy business and management skills, students noted that they walked away feeling they achieved something worthwhile (Theme 7).

The pharmacy organization stakeholders (Table 3 ) also felt that the experimental project was a valuable exercise and provided an overall positive experience (Theme 1). Pharmacy organization representatives also noted that the deliverable provided by the students was useful to the organization. In fact, in some instances, the organizations had already begun implementing the projects developed by the students by semester's end (Theme 2 ). The experimental project also allowed for networking between college faculty members and alumni by meeting the alumni where they work and in their own setting. Moreover, the experimental project allowed the opportunity for some of the efforts of the college to be advertised, and subsequently it became a source of pride to some of the participants (Theme 3 ). In addition to a physical deliverable, students also contributed a unique, outside perspective to the organization that the pharmacy organization partners found useful, noting how the students' perspective allowed the organization to get beyond a group-think mentality (Theme 4). Finally, as expected, there were also challenges discovered during the experimental project. However, none of these challenges were insurmountable and did not affect the overall perceived value of the collaboration in the minds of the pharmacy organizations. One of the stakeholders presented this in terms of a cost-benefit calculation while others identified challenges in communication, similar to what the student teams had noted (Theme 5).

\section{DISCUSSION}

The inclusion of entrepreneurship as a focus area by the CAPE outcomes is a signal to pharmacy educators that reinforcing innovation among student pharmacists is vital to developing well-rounded future providers. ${ }^{1}$ While a growing number of pharmacy schools in the United States have begun programs in or included coursework on entrepreneurship, many still do not afford students these opportunities. Consequently, pharmacy management courses may be the only opportunity to encourage student innovation through required class projects; however, business planning within a controlled environment (ie, confined to a classroom) may not be an ideal exercise to connect curricular content with real-world application. If the goal is to challenge student pharmacists to be innovative thinkers

Table 3. Stakeholder Feedback Themes and Select Responses Related to the Experimental Project

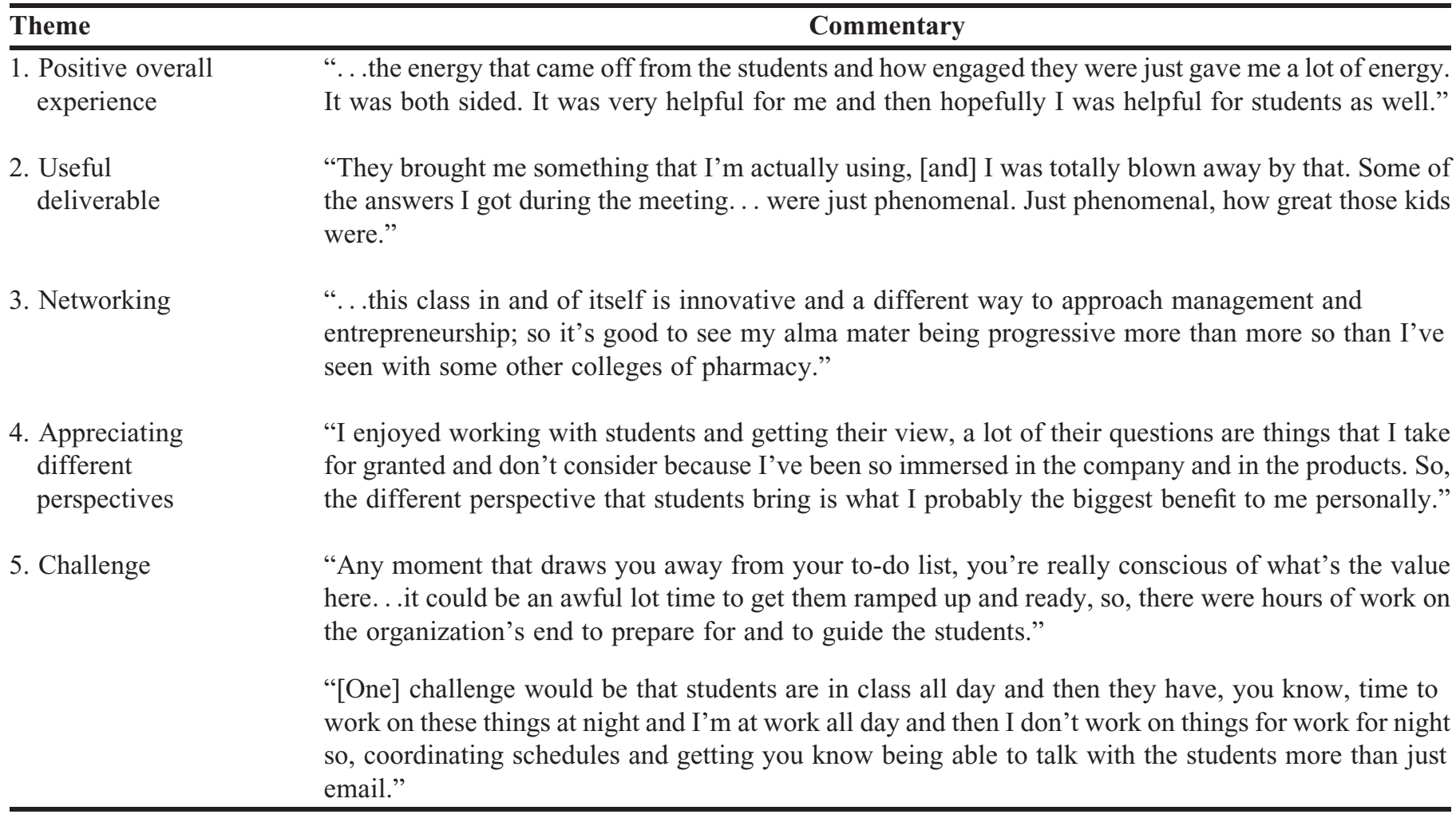




\section{American Journal of Pharmaceutical Education 2018; 82 (5) Article 6279.}

while they absorb requisite content, educators must also push the envelope in terms of providing active learning opportunities where necessary context can be obtained.

The experimental business planning project builds off of the evidence supporting the value of providing students with real-world pharmacy management problem-solving experiences and was conceived and implemented with the guidance and expectations of CAPE and ACPE. ${ }^{16,17,19}$ Specifically, this exercise was intended to be responsive to the call for encouraging students to "apply entrepreneurial skills within a simulated entrepreneurial activity." ${ }^{1}$ In fact, it is arguable that the concept described herein goes beyond responding to Standards and may serve as a leading example of how real-world experiences may supplant simulated exercises, such as the creation of a business plan with no potential for immediate implementation (ie, our "traditional" business plan project). Moreover, such an applied experience arguably provides students opportunities to be simultaneously entrepreneurial, by allowing them to identify opportunities and think of a potential new venture or product, and intrapreneurial, by requiring them to work within the confines of a specific firm. This latter concept, while still relatively new, is one that has garnered attention within pharmacy and may prove to have even more applicability to pharmacists who, by and large, practice within defined environments with set resources yet are settings under which innovation remains important. ${ }^{20,21}$ Nursing schools have recognized the potential for intrapreneurial thinking. ${ }^{22}$ More fully incorporating this concept into pharmacy education may better prepare pharmacy graduates for long-term career development.

Insight collected from students and stakeholders involved with the experimental project support such an exercise as a valuable experience whose real-world nature was viewed as mutually beneficial. Compared to their peers, experimental project students reported multiple benefits from conducting this type of experiential exercise in both the short- and long-term. Perhaps most importantly, this project provided these students with an exercise that led to improved context for pharmacy management material and an experience that allowed them to showcase their problem-solving abilities and marketability in front of a potential employer. Concurrently, the business partners received insight from a third-party source that was actionable and had the potential to further the mission of the firm. All five applied project teams were successful in creating an innovative concept for their assigned firm through a written proposal and presented it to their key contact before the end of the semester. In one instance, a team presented twice upon request from the firm: once for the assigned firm's leadership and another time for the third-party with whom they proposed their partner company collaborate. As a result of the project, student teams proposed, and in one case, created distinct concepts for their partner company. These included the installing of a needed satellite pharmacy within an institution, the use of student-driven MTM services, the creation of a charitable pharmacy toolkit, the incorporation of specific pharmacogenomic testing at community pharmacies, and the expansion of a company's current wellness services to its employees in other states using telephonic MTM mechanisms. To date, all five partnering firms had either adopted the students' proposed concept or planned to implement them at a future date. Consequently, UTCOP benefitted by exposing members of its network to the capabilities of the future pharmacists that it is developing.

An important observation made by both students and stakeholders was the ambiguous nature of the experimental project. In contrast to completing a hypothetical business plan with a defined rubric and well-established expectation, the experimental project mirrored problem-solving as it is likely to occur in an active business environment where structured solutions are not likely to be prevalent. Such ambiguity was purposeful to promote innovative thinking in students while also putting them in scenarios they are likely to encounter irrespective of future practice site. While students pointed this out as a challenge, and even went so far as to dislike this feature, such uncertainty is likely in practice; therefore, gaining practice in managing ambiguity is valuable if they are to contribute to the management of it in the future. A call for focusing on creating leaders and agents of change rather than followers has been made by pharmacy leaders, and projects similar to what was piloted may be an effective vehicle to identify and further develop such future pharmacists. ${ }^{23}$ However, it is important to note that while ambiguity may have been a purposeful method to encourage freethinking on the part of the student groups, the same experience should be avoided in terms of guidance to the partner firms. Those seeking to implement a similar student-firm partnership must be sensitive to the demands of the private sector and set clear expectations and time requirements that the stakeholder, and their management, can work around and anticipate.

These findings were hypothesized at the outset of the term: moving the business plan project into an active business environment would be viewed as a more valuable learning experience than simply requiring students to produce a hypothetical proposal. Consequently, findings of this study reinforce the need for more applied group project exercises, echoing experiences and perspectives at peer institutions. Moving forward, there is a plan to build off of the learnings from this pilot year and expand the concept in years ahead. Ultimately, the aim is to have a large enough pool of partners to tailor opportunities for 


\section{American Journal of Pharmaceutical Education 2018; 82 (5) Article 6279.}

groups of students with interest in like practice sites. As is likely the case for any college instituting a similar concept, the challenge remains in finding a representative set of willing partners who recognize the value of such an exercise for students and have the requisite time and role within their firms to properly facilitate this experience.

This study has limitations. First, students self-selected into groups and then decided upon the type of project thereafter; consequently, it is possible that groups were formed among students interested in a more applied project and such collective interest may have biased the results at the end of the semester. Future comparisons of these project types may benefit from either random student assignment and then project selection or the random assignment of project types to established student groups. Additionally, only the experimental project groups participated in focus groups at the end of the semester, limiting qualitative feedback to the new concept. While qualitative feedback do exist from students completing the traditional project (via course evaluations), only a random subset of UTCOP students provided such information; therefore, it was not possible to extract data from students known to have completed a traditional project. However, as such feedback is given each year, the evaluations from previous years - those providing the impetus for experimenting with a new project type - are likely to parallel the feedback provided in the most recent year as the format of this project has not changed.

\section{CONCLUSION}

A team-based business planning project that requires active involvement with a pharmacy-related firm provides a more real-world problem-solving exercise, generating needed context often missing from simple didactic instruction on pharmacy management topics. Such a mechanism may better educate student pharmacists on operational, financial, and strategic aspects of pharmacy practice and better prepare them to make immediate, innovative impacts on their chosen practice site following graduation.

\section{REFERENCES}

1. American Association of Colleges of Pharmacy. Center for the Advancement of Pharmaceutical Education. https://www.aacp.org/ resource/cape-educational-outcomes. Accessed November 15, 2016. 2. Accreditation Council for Pharmacy Education. Accreditation standards and key elements for the professional program in pharmacy leading to the doctor of pharmacy degree. Standards 2016. https:// www.acpe-accredit.org/pdf/Standards2016FINAL.pdf. Accessed November 15, 2016.

3. Perepelkin J. Redesign of a required undergraduate pharmacy management course to improve student engagement and concept retention. Am J Pharm Educ. 2012;76(10):Article 201.
4. Fink LD. Creating Significant Learning Experiences: An Integrated Approach to Designing College Courses. $2^{\text {nd }}$ ed. San Francisco, CA: Jossey-Bass; 2013.

5. Bloom B, Englehart M, Furst E, Hill W, Krathwohl D. $2^{\text {nd }}$ ed. Taxonomy of Educational Objectives: The Classification of Educational Goals. Handbook I: Cognitive Domain. New York, NY: Addison-Wesley Longman; 1956.

6. Vanevenhoven J. Advances and challenges in entrepreneurship education. J Small Bus Manage. 2013;51(3):466-470.

7. Meyer GD. The reinvention of academic entrepreneurship. J Small Bus Manage. 2011;49(1):1-8.

8. Cook RG, Belliveau P. The Experiential Student Team Consulting Process. Mason, OH: Thomson Publishing; 2006.

9. Heriot KC, Cook R, Jones RC, Simpson L. The use of student consulting projects as an active learning pedagogy: a case study in a production/operations management course. Dec Sci J Inn Educ. 2008;6(2):463-481.

10. Cook RG. Quality field case consulting: new program possibilities. J Small Bus Strat. 2000;11(2):105-107.

11. Cook ED, Hazelwood AC. An active learning strategy for the classroom - "who wants to win. . .some mini Chips Ahoy?" J Account Educ. 2002;20(4):297-306.

12. Skomo ML, Kamal KM, Berdine HJ. A required course in the development, implementation, and evaluation of clinical pharmacy services. Am J Pharm Educ. 2008;72(5):Article 109.

13. Perepelkin J. Redesign of a required undergraduate pharmacy management course to improve student engagement and concept retention. Am J Pharm Educ. 2012;76(10):Article 201.

14. Schumock GT, Stubbings J. How to Develop a Business Plan for Pharmacy Services. Lenexa, KS: American College of Clinical Pharmacy; 2013.

15. National Community Pharmacy Association. Good Neighbor Pharmacy NCPA Pruitt-Schutte Student Business Plan Competition. http://www.ncpanet.org/students/business-plan-competition.

Accessed November 15, 2016.

16. Hicks C, Siganga W, Shah B. Enhancing pharmacy student business management skills by collaborating with pharmacy managers to implement pharmaceutical care services. Am J Pharm Educ. 2004;68(4):Article 94.

17. Moultry AM. A mass merchandiser's role in enhancing pharmacy students' business plan development skills for medication therapy management services. Am J Pharm Educ. 2011;75(7):Article 133. 18. Kim SE, Whittington JI, Nguyen LM, Ambrose PJ, Corelli RL. Pharmacy students' perceptions of a required senior research project. Am J Pharm Educ. 2010;74(10):Article 190.

19. Slavcek RA, Waite NM, Jennings B. Shaping pharmacy students' business and management aptitude and attitude. Curr Pharm Teach Learn. 2016;8(5):672-680.

20. Taylor CT, Adams AJ, Adams EL, et al. Report of the 2014-2015 Professional Affairs Standing Committee: producing practice-ready pharmacy graduates in an era of value-based health care. Am J Pharm Educ. 2015;79(8):Article S12.

21. Hohmeier KC, Gatwood J. Toward intrapreneurship in pharmacy education. Am J Pharm Educ. 2016;80(3):Article 53.

22. Manion J. Enhancing career marketability through intrapreneurship. Nurs Admin Quart. 2001;25(2):5-10.

23. Svensson CK, Ascione FJ, Bauman JL, et al. Are we producing innovators and leaders or change resistors and followers? Am J Pharm Educ. 2012;76(7):Article 124. 